\title{
Indices-Based Evaluation of Spatiotemporal Distribution of Drought Within Derbendkhan Dam Watershed
}

\author{
Mahmoud S. Al- Khafaji ${ }^{a^{*}}$, Rusul A.H. Al- Ameri ${ }^{\text {b }}$ \\ ${ }^{a}$ Civil Engineering Department, University of Technology, Baghdad, Iraq, 41100@uotechnology.edu.iq \\ ${ }^{\mathrm{b}}$ Civil Engineering Department, University of Technology, Baghdad, Iraq, Rusulalameri93@gmail.com \\ *Corresponding author.
}

Submitted: $17 / 08 / 2020$

Accepted: $30 / 11 / 2020$

Published: 25/06/2021

\section{K E Y W O R D S}

Drought frequency analysis, Diyala River, RDI, SPI, SDI.

\begin{abstract}
A B S T R A C T
Drought is one of the most significant natural disasters in Iraq. It has a strong impact on the water resources in Iraq. Consequently, it causes massive environmental damage, economic deficiency, and social problems to the country. Therefore, more considerations towards the study and management of drought has become of vital importance in recent decades.

In this paper, three drought indices (DIs) were computed for evaluation of the spatiotemporal of drought within Derbendikhan Dam Watershed $(D D W)$ in the Diyala River Basin, Iraq. Based on the monthly weather data for the period (1984 - 2013) downloaded from the Climate Forecast System Reanalysis (CFSR) for eight stations located within DDW. The Reconnaissance Drought Index (RDI), standardized precipitation index (SPI) and Streamflow Drought Index (SDI) at 12-month time scale were computed to assess droughts in the DDW. For each index, the temporal variations of the drought severity and Drought Frequency Patterns (DFPs) for the period (1984 - 2013) were computed and analyzed. In addition, spatial distributions of the drought severity for each index were mapped and investigated. Accordingly, the DFPs were compared to specify the dominant and/or more frequent DFPs. The results show that the performances of different DIs are strongly correlated with the dominant factors of droughts and drought duration. Also, the SPI and SDI are less accurate than the RDI when both precipitation and evaporation are the main factors controlling the drought events. However, the SPI and SDI indices are identical in the same proportions of the dry years which are less than the ratio of dry years to an RDI, but the severity of the drought from the SDI results is higher than the severity of the drought relative to the SPI and RDI. The three indices indicate that the Eastern region is drier than the Western region, which is somewhat wet.
\end{abstract}

\footnotetext{
How to cite this article: M. S. Al- Khafaji, R. A. Al- Ameri, "Indices-Based Evaluation of Spatiotemporal Distribution of Drought Within Derbendkhan Dam Watershed," Engineering and Technology Journal, Vol. 39, No. 06, pp. 893-914, 2021.

DOI: https://doi.org/10.30684/etj.v39i6.1802

This is an open access article under the CC BY 4.0 license http://creativecommons.org/licenses/by/4.0
} 


\section{INTRODUCTION}

Worldwide drought is one of the more critical natural disasters. It has serious effects on the environment, agriculture, economy as well as all human activities. Despite the fact that most natural disasters are either of short period of time or small spatial extent events, a drought, however, is a cumulative over a long period of time and extends over a large spatial extent. Therefore, analysis and assessment of drought magnitude and severity is of vital important for sustainable management of Earth's environment and resources as well as all human activities.

Droughts have caused a prevalent environmental and societal effects and multiple droughts may exacerbate the desertification and land degradation, as it happened after the destructive droughts of the Sahel from the period of (1960-1970) [1]. In general [2], defined the drought as a moisture deficiency. Unlike other natural disasters, such as earthquakes, volcanic eruptions, tropical tornadoes, and floods growing, drought is a quietly increasing catastrophe, as it evolves, during the hydrological cycle and its ongoing consequences often appear after its ends. [3]. Generally, drought can be classified into four types: meteorological drought, agricultural drought, hydrological drought $[4,5]$, and groundwater drought. Deficiency in the average precipitation during a specific period within a specific region causes the meteorological drought. Whereas, a lack of providing the crops water demands due to the deficiency in soil moisture causes agricultural drought. In addition, decreasing of water levels in lakes, reservoirs and rivers due to the deficiency of streamflow is referred to as hydrological drought. However, the practical consequences of these four types of drought on some economic and human activity as well as on the quality of human life is linked to the socio-economic drought. Recently, a groundwater drought is suggested to relate the effects and consequences of ground water deficiency [6].

Drought may result in long-term environmental, economic and social impacts, which affects great populations and areas. Approximately half of the Earth's land area is sensitive to a drought [7]. The International Disaster Database (EM-DAT, 2013) [8], reported that more than 11 million people are killed and more than 2 billion people are affected due to drought calamity from 1900 to 2011. As climate change, increasing the temperature and aggravate dry conditions, Dai et al. 2004 [9] proved the increasing number of drought events.

Understanding of the spatiotemporal growth of drought events is important for planning drought, decreasing its impact and response. The severity, duration, frequency and spatial extents of drought are the vital characteristics for understanding and assessment of droughts. Intensity of the meteorological drought is usually assessed by the negative deviations of precipitation from its normal rates [10]. Over the years, many droughts indices (DIs) were developed and utilized by the climatologists and meteorologists. Those ranged from a simple indices such as percentage of normal precipitations and precipitations percentiles to the more complicated indices, such as the Palmer Drought Severity Index (WMO, 2012).

There are many studies that have been presented for the assessment of drought in Iraq. Most of these studies adopted the meteorological parameters as the main assessment variables, such as Hameed, et al 2018; Awchi and Jasim, 2017; AL-Timimi 2012and Rasheed 2010 [11-14]. In addition, there are a few studies that considered the agricultural and hydrological droughts such as AL-Timimi 2012 and Al-Mohseen 2010, [13, 15]. In this paper, the temporal and spatial distribution of three DIs, namely SPI, RDI and SDI in the Derbendikhan Dam Watershed (DDW) within the Diyala River Basin area in Iraq were computed by using the DrinC software based on monthly precipitation, air temperatures supplied by Climate Forecast System Reanalysis (CFSR) for eight stations and streamflow from one station to assess and evaluate the meteorological and hydrological drought in DDW.

The Standardized Precipitation Index (SPI) which developed by the American scientists, McKee, Doesken and Kleist in 1993. The SPI is a powerful and flexible index that is simple to calculate. In fact, precipitation is the only required input parameter. In additions, it is just as effective in analyzing wet period/cycle, as it is in analyzing dry period/cycle. Recently, a modern index termed Reconnaissance Drought Index (RDI) has been presented for droughts monitoring and assessment. Its computation depends on the precipitation and potential evapotranspiration. Furthermore, Streamflow Drought Index SDI, is successfully and commonly applied method in the analysis and assessment of the hydrological drought in many studies, (such as Ozkaya and Zerberg 2013; Soumyashri and Patil, 2016; Nalbantis, 2008) [16-18]. This index is depending only on the streamflow. 


\section{Methods AND Materials}

\section{Methods}

The methodology of this paper began with computation of the average monthly SPI, RDI and SDI indices by using the DrinC software. These indices were computed for the period 1984-2013 based on the CFSR weather data. Only this period is available in CFSR, where there is only one station in the region, which is Khanakheen Gauge Station, and it has very little data for a few years. Therefore, the CFSR data was used to compute the SPI and RDI, and the streamflow data was used to compute for the SDI. Then, Drought Frequency Patterns (DFPs) were computed for each index to determine droughts recurrence intervals and the exceedance probability and/or return periods of specific duration and/or severity. Moreover, the spatial distribution for drought in DDW was mapped utilizing the Surfer13 software for both SPI and RDI only. However, the streamflow was only available for one station. Therefore, the spatial distribution of SDI was not mapped and only temporal distribution was computed.

\section{Meteorological Drought Indices}

Drought indices are a quantitative description for the droughts severity through representation of the values of the effective variables, such as precipitations and evapotranspiration, by one value ranging between 0 to 100 percent. Such an index is more easily useable than raw data values of one or more variables with different impact levels on the drought. The natures of DIs reflect different conditions and events; these indices can reflect the climate dryness anomalies (based on precipitations) or coincide with a delayed hydrological and agricultural effects, such as loss of soil moistures or decrease of reservoir levels. Furthermore, the classification of DIs can also be based on the adopted metrological data and the applied approach and method. In this paper, three DIs were considered and the theoretical background of these indices is discussed below.

\section{Standardized Precipitation Index (SPI)}

McKee et al. in 1993 presented SPI for monitoring droughts. The fitting of gamma distributions was used to obtain stations frequency distributions of total rain. According to McKee et al (1993) [19] this index was determined based on different time periods such as quarter year, half year, one year, two years, three years, and four years. These periods reflects the effects of dryness and wetness on the available quantity of water resources. Short periods of precipitation deviation impacts soil wetness and long period's precipitation aberrations reflects impact on the available water [20]. For this index, the negative value indicates less than average precipitations whereas the positive indicates is more than average [21]. The period of recorded data must be more than 30 years, because this index is fitted to this period as well and it must be comparable with other regions of different climate conditions [22]. Classification of metrological droughts based on the SPI values is shown in Table I [23]. Calculations of this index include fitting a gamma probability functions to give precipitation time series. This functions is determined according to the following equations [24]:

$$
\text { If for } x, \beta>\text { zero then } x=\frac{1}{\beta \alpha \Gamma(\alpha)} x^{\alpha-1} e^{-x / \beta}
$$

Where: $\mathrm{x}$ is the precipitation depth in $\mathrm{mm}, \alpha$ and $\beta$ are the shape parameters and $\Gamma(\alpha)$ is the Gamma function of $\alpha$.

$\Gamma \alpha=\int_{0}^{y} y^{\alpha-1} e^{-y} d$

$\alpha$ and $\beta$ parameters are computed as follow:

$$
\begin{aligned}
& \alpha=\frac{1}{4 * A}\left(1+\sqrt{1+\frac{44}{3}}\right) \\
& \beta=\frac{X^{-}}{\alpha} \\
& A=(\bar{x})-\frac{\sum \ln (\mathrm{x})}{n}
\end{aligned}
$$


Where, $\bar{x}$ is average precipitation depth in $\mathrm{mm}, \mathrm{n}$ is number of precipitation data.

The cumulative probability of the measured precipitation for a given time period can be calculated as follow [23, 24]:

$\mathrm{x}=\frac{1}{\beta \alpha \Gamma(\alpha)} \int_{0}^{x} x^{\alpha-1} e^{-x / \beta} \mathrm{dx}$

$\mathrm{H}(\mathrm{x})=(1-\mathrm{Q}) G_{x}+\mathrm{Q}$

$S P I=\frac{2.515517+0.802853 * \mathrm{t}+0.010328 * \mathrm{t}^{2}}{1+1.432788 * \mathrm{t}+0.189369 * \mathrm{t} 2+0.001308 * \mathrm{t}^{3}} \quad$ for $0<\mathrm{H}(\mathrm{x})<=0.5$

When $t=\sqrt{\ln \frac{1}{[\mathrm{H}(\mathrm{x})]^{2}}}$

$S P I=-\frac{2.515517+0.802853 * \mathrm{t}+0.010328 * t^{2}}{1+1.432788 * \mathrm{t}+0.189369 * \mathrm{t} 2+0.001308 * \mathrm{t}^{3}} \quad$ for $0.5<\mathrm{H}(\mathrm{x})<=1$

$$
\begin{gathered}
\text { When } t=\sqrt{\ln \frac{1}{\lfloor 1-\mathrm{H}(\mathrm{x})\rfloor^{2}}} \\
S P I=\frac{\ln (\mathrm{xi})-\mu}{\alpha}
\end{gathered}
$$

At the arithmetic level, sometimes it can be more functional to standardize the precipitation data straight from a fitted normal distribution where possible. Accordingly, the SPI can be computed using equation (13):

$$
S P I=\frac{x i-\mu}{\alpha}
$$

Where: $\mathrm{x}, \mu$ and $\sigma$ are the precipitation, average and standard deviation of precipitation, respectively.

TABLE I: Classification of metrological droughts based on the SPI values [23].

\begin{tabular}{cc}
\hline \hline SPI Values & Classification \\
\hline 2.0 or more & Extremely wet \\
\hline 1.5 to 1.99 & Very wet \\
\hline 1.0 to 1.49 & Moderately wet \\
\hline 0.99 to 0 & Mild wet \\
\hline 0 to -0.99 & Mild drought \\
\hline-1.0 to -1.49 & Moderately dry \\
\hline-1.5 to -1.99 & Severely dry \\
\hline-2 or less & Extremely dry \\
\hline
\end{tabular}

The SPI is a flexible index that can be calculated for several timescales. SPI indices with a shorter date ranges, such as 1, 2 or 3 months SPIs, can also provide early warnings of droughts and helps evaluation of the severity of the droughts. Also spatially consistent, it allows users to make comparisons between different sites at different locations, collect climates. Its probabilistic nature gives it the historical context, and it is well suited for decision-making.

The weakness of this index, however, is based only on the precipitation. Also, no soil waterbalance components, thus no ratios of evapotranspiration/potential evapotranspiration, (ET/PET) that can be calculated. 


\section{Reconnaissance Drought Index (RDI)}

After a methodical investigation of the various indices utilized to identify and evaluate the severity of meteorological drought, it was found that in spite of the all these indices were useful, none of them seem to be interesting for worldwide application. However, the SPI has become very common due to its less data requirements. A new exploration drought identification and assessment index was first presented in the coordinating meeting of MEDROPLAN [25], while, a more comprehensive description was presented in other publications [26, 27]. This index is referred to as the Reconnaissance Drought Index (RDI). It depends on the ratio of accumulated amounts of precipitation and potential evapotranspiration (PET). Classification of the metrological drought based on the RDI values is shown in Table II [28]. This index is compute based on equations (14) to (17):

$$
\alpha \mathrm{o}^{\mathrm{i}}=\frac{\sum_{j=1}^{12} \mathrm{R} i j}{\sum_{j=1}^{12} \mathrm{PET} i j}
$$

Where: Rij and PETij are precipitation and potential evapotranspiration of the $j^{\text {th }}$ month of the $i^{\text {th }}$ year.

$$
\text { RDIstk }^{i}=\frac{\mathrm{yk}^{\mathrm{i}}-\mathrm{A}\left(\mathrm{y}^{\mathrm{K}}\right)}{\sigma y^{\mathrm{K}}}
$$

Where: $\mathrm{yk}^{\mathrm{i}}=\ln \left(\alpha \mathrm{o}^{\mathrm{i}}\right), \mathrm{A}\left(\mathrm{y}^{\mathrm{K}}\right)$ and $\sigma \mathrm{y}^{\mathrm{K}}$ are the average and standardized deviation, respectively. Based on the RDI index, the metrological drought is classified as listed in Table III (Shah et al, 2013). In this paper, the PET was computed by using the Thornthwait Method, equations (16) and (17), [39]:

$$
\begin{aligned}
& \text { PET }=16\left(\frac{D T}{360}\right)(10 \mathrm{tn} / \mathrm{J})^{\mathrm{K}} \mathrm{mm} / \text { month } \\
& \mathrm{J}=\int_{i=1}^{12} i \\
& \quad \mathrm{i}=[\operatorname{tn} / 5]^{1.514} \\
& \quad \mathrm{k}=(675 \times 0.000000001) \mathrm{J}^{3}-(771 \times 0.0000001) \mathrm{J}^{2}+(179 \times 0.0001) \mathrm{J}+0.492 \\
& \quad \text { Where: }
\end{aligned}
$$

PET $=$ Potential evapotranspiration for each month $(\mathrm{mm} /$ month $), t=$ Mean monthly temperature $\left(\mathrm{C}^{\circ}\right), \mathrm{n}=$ Number of monthly measurements, $\mathrm{J}=$ Annual heat index $\left(\mathrm{C}^{\circ}\right), \mathrm{i}=$ monthly temperature parameter $\left(\mathrm{C}^{\circ}\right)$, D: Number of the days a month. T: Average number of sunshine hours.

TABLE II: Classification of the metrological drought based on the RDI values [28]

\begin{tabular}{cc}
\hline \hline RDI Values & Classification \\
\hline 2.0 or more & Extremely wet \\
\hline 1.5 to 1.99 & Very wet \\
\hline 1.0 to 1.49 & Moderately wet \\
\hline 0.99 to 0 & Near normal \\
\hline 0 to -0.99 & Mild drought \\
\hline-1.0 to -1.49 & Moderately dry \\
\hline-1.5 to -1.99 & Severely dry \\
\hline-2 or less & Extremely dry \\
\hline
\end{tabular}

RDI is physically sound, since it calculates the aggregated deficits between the precipitation and the evaporative demands of the atmosphere. It can be calculated for any periods of time (e.g., 1 month, 2 months etc.). The calculation always leads to a meaningful figure. Also, it can be effectively associated with the agricultural droughts. Furthermore, it's directly linked to the climatic condition of the region since for the yearly values, it can be compared with FAO Aridity Index. Moreover, the RDI can be used under "climate instability" condition for examining the significance of various changes of climatic factor related to water scarcity. 
From the above advantages, it can be concluded that RDI is an ideal index for the reconnaissance assessment of droughts severity for general uses giving comparable results within large geographical area, such as, the Mediterranean [30].

\section{Hydrological Drought Index}

Streamflow Drought Index (SDI)

Recently, Nalbantis and Tsakiris 2009 [31] developed SDI to characterize the hydrological drought based on the same calculation methodology of the SPI. The time series of observed monthly streamflow volumes $(\mathrm{Q} i, \mathrm{j})$ can be used to compute the cumulative streamflow volume $(\mathrm{Vi}, \mathrm{k})$ as follows [32]:

$V_{i, k}=\sum_{j=3(k-1)+1}^{3 k} Q_{i, j} \quad k=1,2,3,4$

$V_{i, k}=\sum_{j=6(k-1)+1}^{6 k} Q_{i, j} \quad k=1,2$,

$V_{i, k}=\sum_{j=1}^{12} Q_{i, j}$

$$
i=1,2,3, \ldots \ldots \ldots, \quad j=1,2, \ldots \ldots \ldots \ldots . .12
$$

These computations was performed by suing reference periods of 3 months for equation 18, 6 months for equation 19 and 12-months for equation 20 . Where $\mathrm{i}, \mathrm{j}$ and $\mathrm{k}$ are the hydrological year, months of this year and reference period respectively. For each $\mathrm{k}$ of the $\mathrm{i}^{\text {th }}$ hydrological year, the SDI is computed based on the $\mathrm{V}_{\mathrm{i}, \mathrm{k}}$, by using Equation (21):

$$
S D I_{i, k}=\frac{V_{i, k}-\bar{V}_{k}}{S_{k}} \quad i=1,2, \ldots \ldots, \quad k=1,2,3,4
$$

Where $V_{k}$ and $S_{k}$ are the mean and standard deviation of the cumulative streamflow volumes of the reference period $k$.

Based on the computed value of SDI, Hydrological drought can be classified in to eight classes as shown in Table III [31]. Hydrological drought is indicated when the SDI value is below zero and the drought severity increases with the decrease of the SDI value below Zero. However, positive SDI values indicate no drought (wet conditions).

TABLE III: $\quad$ Classification of hydrological drought based on the SDI values [31]

\begin{tabular}{cc}
\hline \hline SDI Values & Classification \\
\hline 2.0 or more & Extremely wet \\
\hline 1.5 to 1.99 & Very wet \\
\hline 1.0 to 1.49 & Moderately wet \\
\hline 0.99 to 0 & Mild wet \\
\hline 0 to -0.99 & Mild drought \\
\hline-1.0 to -1.49 & Moderately dry \\
\hline-1.5 to -1.99 & Severely dry \\
\hline-2 or less & Extremely dry \\
\hline
\end{tabular}

Return Period and Exceedance Probability

Yevjevich, 1967 [33] presented the theoretical concepts of runs method to compute the return periods. Also, many studies followed this concepts to derive the probability distributions and moments of run length, and the first and second moment of run sums for the precipitations series and annual streamflow assuming independents and Markov-dependent series, (e.g., Downer et al. 1967; Llamas and Siddiqui 1969;, 1980; Dracup et al. 1980; Sen 1976; Frick et al. 1990; Fernandez and 
Salas 1999; Loaiciga and Leipnik 1996;) [34-40]. In addition, Lloyd 1970, Loaiciga and Mariño 1991 and Fernandez and Salas 1999 [41, 42, 39] defined the return periods as the average elapsed time between the occurrences of the specified events, i.e., floods exceeding the given design floods. Vogel 1987; Fernandez and Salas 1999 [43, 39] defined the return periods as the average time e.g., in years to the first occurrences of a specified events. Douglas et al. 2002 [44] provided the concepts of calculating the return periods of droughts events with durations greater than or equal to a critical values. This was based on assuming that a stationary two-state Markov chain can models the sequence of wets and dry years. Then, Chung and Salas, 2000 [45] developed these formulations, assuming low-order discrete autoregressive moving average models.

In this paper, the average elapsed time, or mean interval time, between two drought events with a fixed severity or greater was adopted to compute the return period of the drought. However, the exceedance probability computed from the law (1/return period).

\section{Materials}

\section{Study Area}

The Diyala River Basin is a one of the main tributaries of a Tigris River. The river's watershed covers about $32600 \mathrm{~km}^{2}$, located between the latitudes $33.216^{\circ} \mathrm{N}$ and $35.833^{\circ} \mathrm{N}$ and the longitudes $44.500^{\circ} \mathrm{E}$ and $46.833^{\circ} \mathrm{E}$, [46]. The river originate from Zagros Mountains near the Hammadan City then reached the Tigris River South of Baghdad City with a total lengths of about $445 \mathrm{~km}$. Construction of Darbandkhan and Hemrin Dams divides the watershed into three part: the upper part is the Darbandekhan Dam Watershed (DDW), the middle part is the Hemrin Watershed, and the last part, is located between Hemrin Dam and the outfall of the Diyala River in Tigris River [47]. Derbendekhan Dam: is an Earth Dam, constructed in the upper part of Diyala River in the year 1961, approximately about $230 \mathrm{~km}$ Northeast of Baghdad, for multiple purposes such as a protecting Baguba and Baghdad from the floods, irrigation, and the hydropower generation. DDW is the largest water supplier of the Diyala River located between latitudes $35.818^{\circ} \mathrm{N}$ and $34.223^{\circ} \mathrm{N}$ and longitudes $45.28^{\circ} \mathrm{E}$ and $47.96^{\circ} \mathrm{E}$. It is covers $16750 \mathrm{~km}^{2}, 18.4 \%$ inside Iraq, and the remainder in Iran, with the mean daily average flow to Darbandekhan Reservoir of $170 \mathrm{~m}^{3} / \mathrm{sec}$ (Ministry of Water Resources (MoWR) Iraq, 2018, unpublished the data). This watershed is located in a semi-aired region of the Middle East, with an average yearly precipitations of about $420 \mathrm{~mm}$ and an average temperatures of $36{ }^{\circ} \mathrm{C}[49]$.

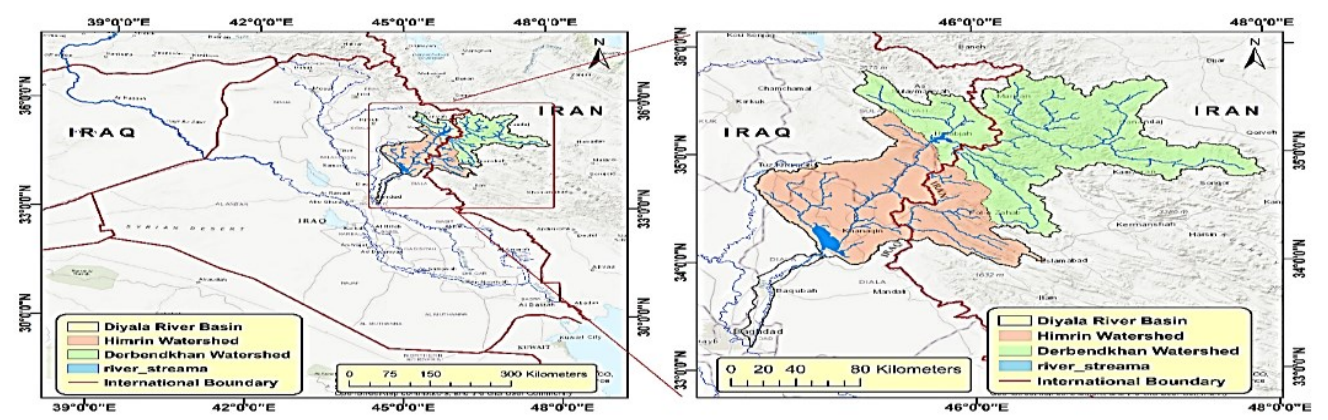

Figure 1: Map of the Diyala River Basin [49].

\section{Data Collection}

In this paper, two types of meteorological data were used to compute the RDI index and SPI index. These data were monthly average precipitation and average temperatures were collected from CFSR. The CFSR contains global weather data produced by the National Weather Service (NWS) and the National Centers for Environmental Prediction NCEP of the Global Forecast System for 30 years from 1984 to 2013 (only these periods were available in the CFSR), and one type of Hydrological data used to compute SDI index was streamflow of Derbendikhan Dam for the period from 1984 to 2013 supplied by the Iraqi National Center for Water Resources. Figure 2 illustrate the input data that used to compute the RDI index and SPI index (Precipitation and potential evapotranspiration). 


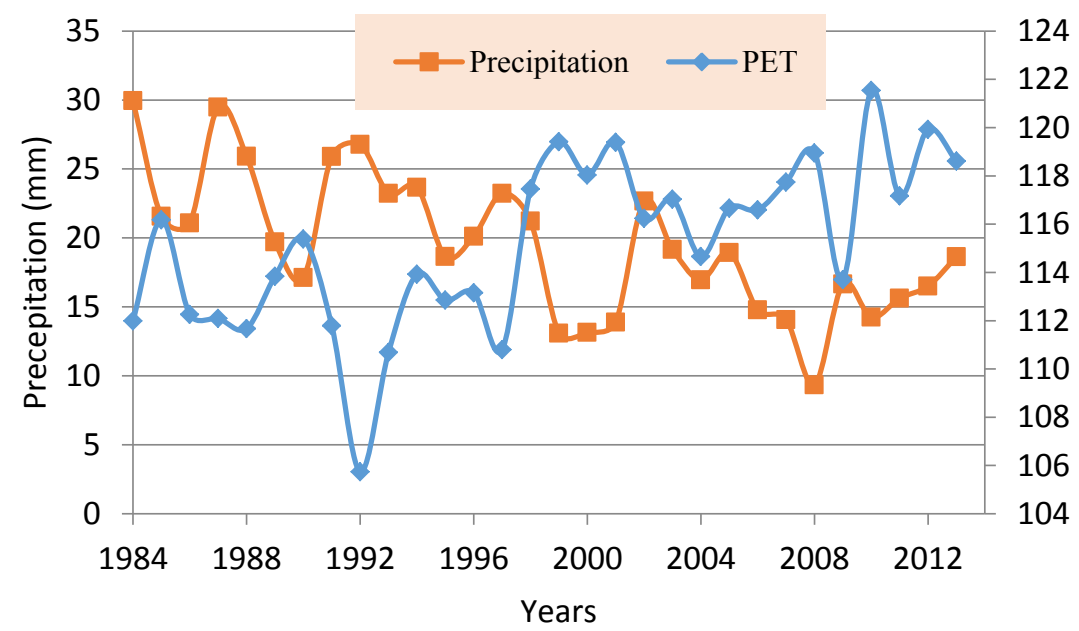

\section{$\frac{\bar{\xi}}{\underline{\underline{g}}}$}

Figure 2: Precipitation for periods from 1984 to 2013 used to compute SPI and RDI, and PET to compute RDI.

\section{RESULT AND DISCUSSION}

\section{Computation of Temporal Distribution of Drought indices}

\section{A. Computation of SPI}

To study the succession of droughts and wets, SPI values were adopted for 12 months, as they covered the annual precipitations of the stations during a year. Figure 3 shows the SPI values for the period 1984 - 2013. The SPI classification for the study area ranges from mild wet to mild drought. It is also noted that the number of dry years is less than the wet years, where the percentage of dry years is $46 \%$ and the percentage of wet years is $53 \%$. The period $1984-1998$ was mild wet, except for the years 1989, 1993 and 1996 which recorded a mild drought while the period 1999-2013 witnessed records of mild drought, except for the years 2002, 2004, 2006 and 2009 where their records were mild wet.

Figure 4, illustrates the number of repetitions of consecutive dry years and exceedance probability, as is evident, the maximum dry period is four consecutive years, and it occurs with a return period of 26 years with a $4 \%$ probability. This figure also shows the relationship between droughts periods and frequency as well as droughts periods and exceedance probability. Hence, it becomes clear that when drought period increase, the frequency and the probability decrease. In this period, the most common event is a one year drought, it occurred every four years, followed by two consecutive drought years.

It is clear from these results that the period $1984-2013$ is almost a wet period that does not suffer from drought, because the ratio of dry years is less than the wet years. It is not possible to say that these results are $100 \%$ reliable, as this index depends on one factor, which is the precipitation. 


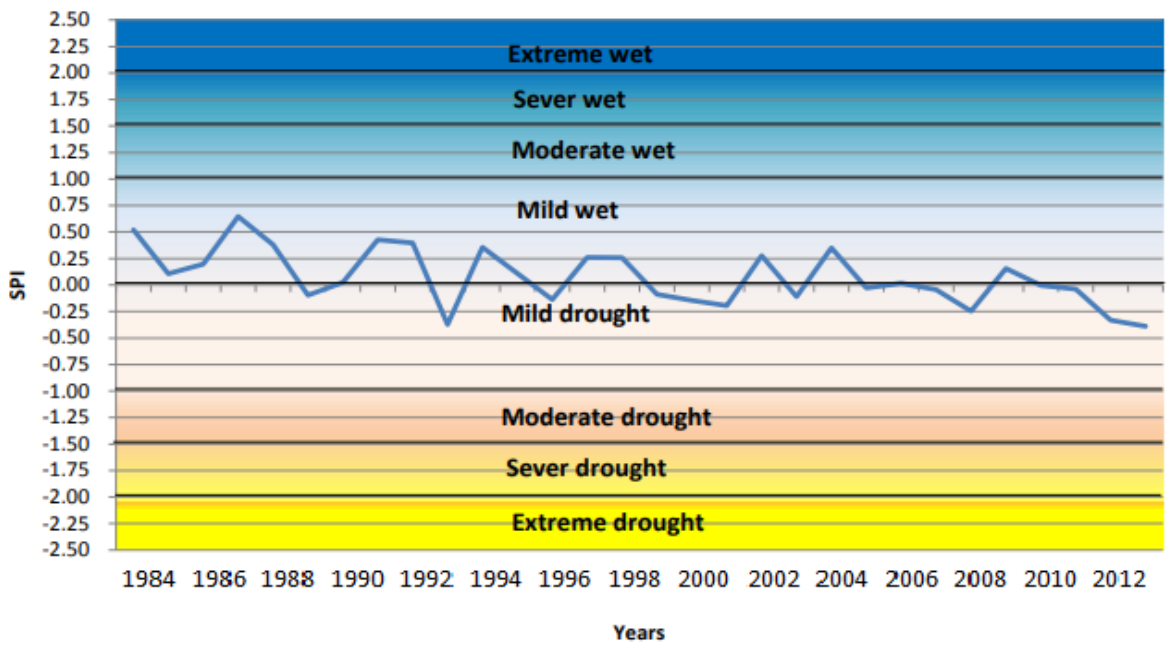

Figure 3: SPI for the period from 1984-2013.

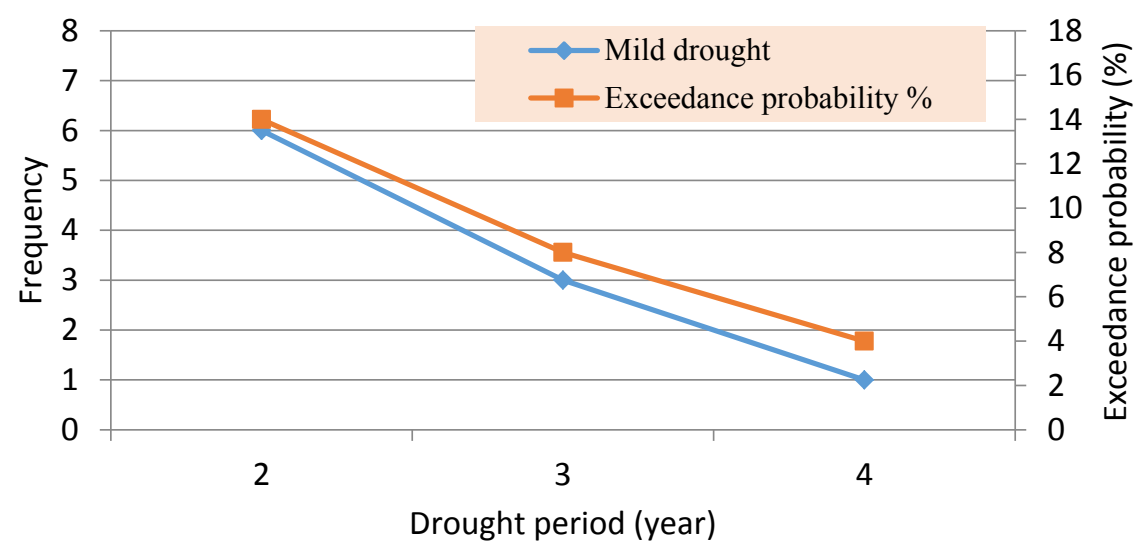

Figure 4: Drought (Mild to extreme drought) successive reoccurrence interval and exceedance probability versus frequency, for the period 1984-2013.

\section{B. Computation of RDI}

Results of this index (also depending on12-month RDI) indicate that the region suffered from long periods of droughts, in contrast to the SPI results. The dry year's ratio was about $66 \%$, while the wet years amounted to $34 \%$. The RDI values ranged from near normal to mild drought according to the index classifications, see Table I.

The study period is divided into two parts. The first part is the period 1984- 1995 and it is considered a wet period, because it has eight wet years and dry years reached three years. While the second part of the period extending from 1995 to 2010 is a dry period, where all the years were mild drought. Figures 2 demonstrated that the precipitation decreased during this period and is accompanied by an increase in potential evapotranspiration, which caused this drought periods. Figure 5 illustrates the RDI during the period 1984- 2013.

Figure 6 shows the repetition of the consecutive dry years and their repetition, as well as the exceedance probability. It is clear from this figure that the recurrence of the two consecutive dry years occurred sixteen times and is concentrated in the period 1995-2010. Also, they occurred in the eighties period followed by repetition from three consecutive years to sixteen years and these occurred only in the period 1995-2010, which is the drier period. Furthermore, this figure shows that the most frequent recurrence is the repetition of two consecutive dry years, as it occurs about every four years with probability of $25 \%$, compared to the rest of the repetitions of three to sixteen repetitions that occur with lower proportions and double return periods more than twice for the period of two consecutive years. 


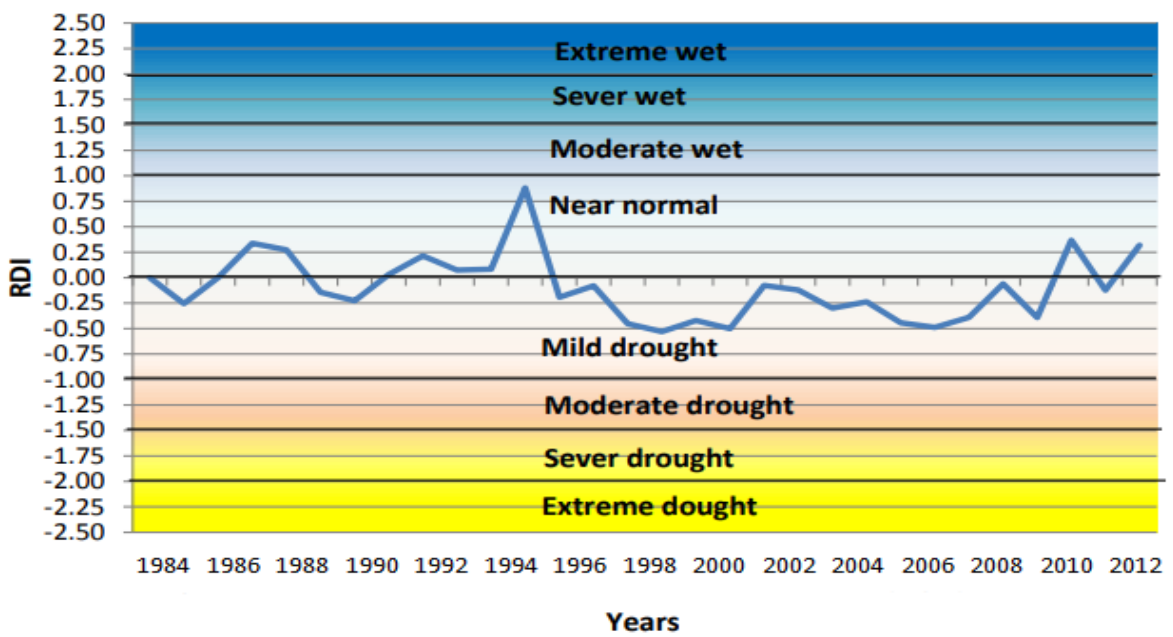

Figure 5: RDI for period 1984- 2013.

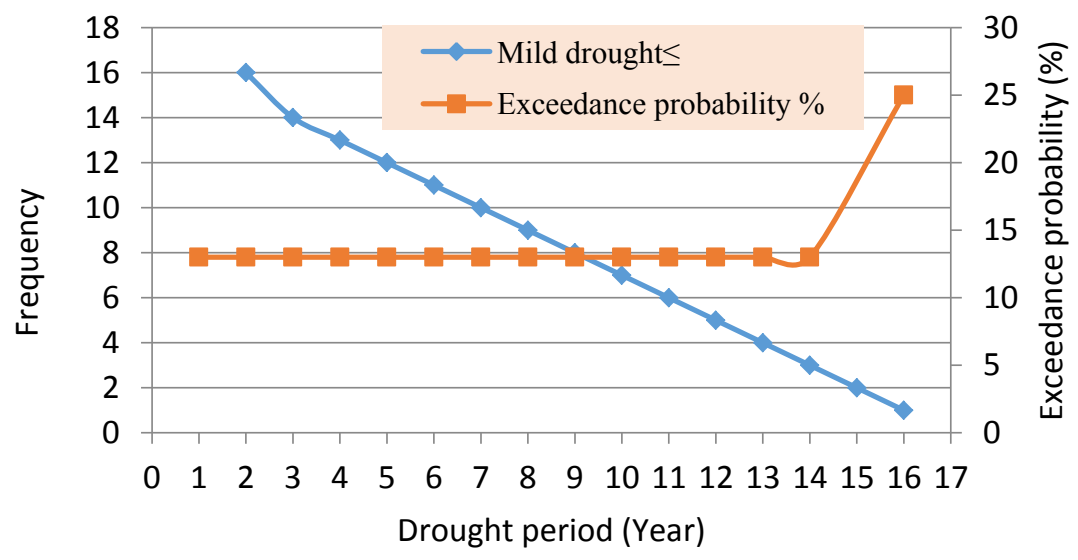

Figure 6: Drought (Mild to extreme drought) successive reoccurrence interval and exceedance probability versus frequency, for the base period 1984- 2013.

\section{Computation of SDI}

Based on available data of monthly streamflow for one gauging station, the SDI values were computed to assess the severity of the hydrological drought. The calculated SDI (12-SDI) values were classified based on Table III. The results shown in Figure 7 represent the values of annual SDI. For this station, the most moderate drought occurred during 2000, 2001, 2008, 2011, 2012 and 2013. While the mild drought occurred during 1997, 1999, 2002, 2004, 2006, 2007, 2009 and 2010. The most wet periods was recorded during 1984 - 1996 and 1998, 2003 and 2005. These wet periods ranged between moderate wet to mild wet. The results of this index are similar to the results of the SPI in that the ratio of dry years is less than wet years. It reaches $46 \%$ and $53 \%$ for dry and wet year respectively, but they differ in their intensity. For wet years, their intensity ranges from moderate wet to mild wet. While dry years have a severity ranging from moderate drought to mild drought.

Figure 8 shows that the moderate drought was repeated for consecutive years more than mild drought. As it is repeated for two and three consecutive years, it occurs every thirteen and fifteen years, respectively. While mild drought repeats for two years in a row and did not repeat for more than this, while it occurs every nine years. 


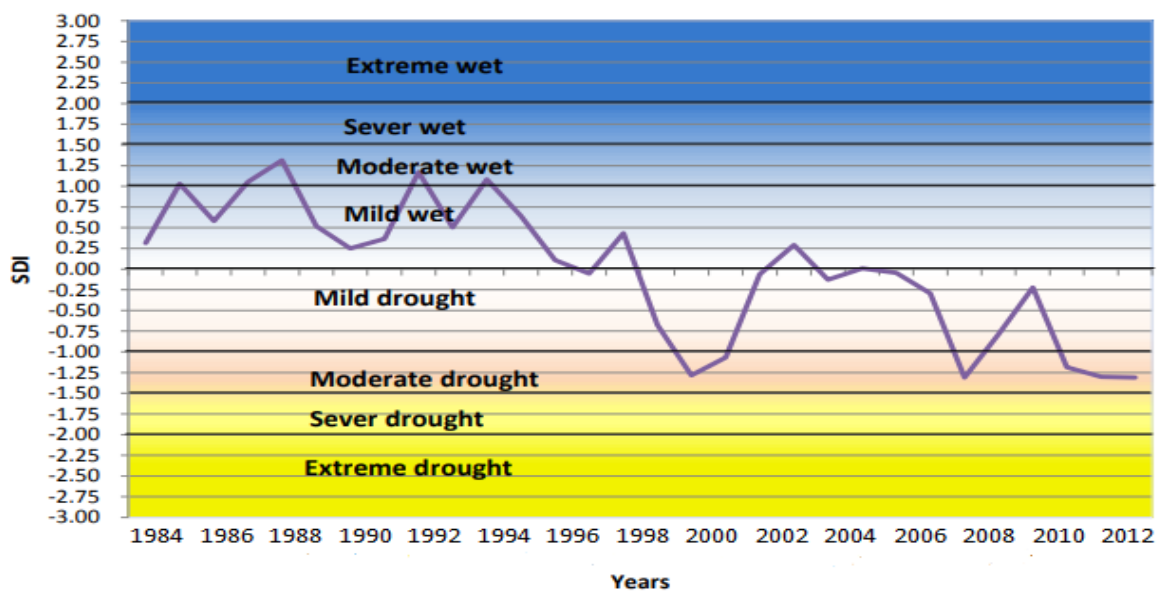

Figure 7: SDI for Period from 1984 to 2013.

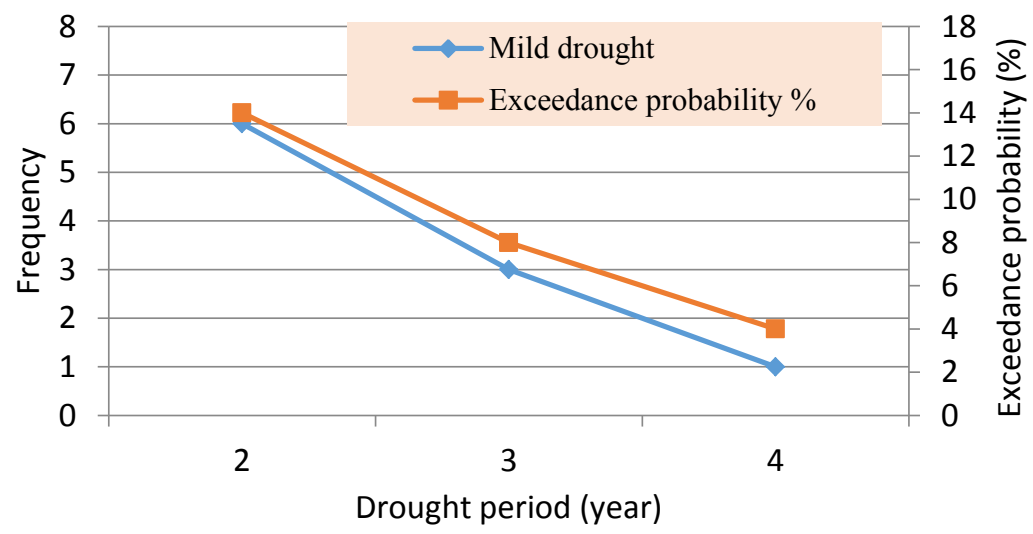

Figure 8: Drought (Mild to extreme drought)successive reoccurrence interval and exceedance

Probability versus frequency, for the period 1984-2013.

\section{Spatial Distribution of Drought Indices}

The daily data was downloaded from CFSR for precipitations and temperatures from eight stations located within Derbendkhan Watershed. This data was converted to monthly data to utilize in the DrinC software and then to compute SPI and RDI indices for each station. Then, the spatial distributions of the indices were mapped utilizing the Surfer13 software.. While the SDI monthly data that was used in the DrinC program is from one station only. So, a temporal analysis was done of the results of the index only and did not work for it maps of spatial distribution. For this, results below are for the two indices SPI and RDI.

\section{A. Spatial Distribution of SPI}

Figure 9 illustrates the spatial distribution of drought according to the SPI results computed from the DrinC software and mapping every two years by the Surfer13 program for eight stations within the watershed. The values of SPI for the years 1984, 1985 and 1986 ranged from 0.1 to 0.65 which is mild wet. Its intensity is distributed in the Western, Northwest and Southwestern parts. While decreased gradually towards the East, North and Southeast. As for the year 1990, the values of the index ranged from -0.05 to 0.08 . The drought covers about $28 \%$ of the watershed area distributed over the eastern and northeastern and southeastern parts with an area of $4714 \mathrm{~km}^{2}$. The SPI intensity decreases towards the center until the wet area begins and increases towards the west. The wet area covering $72 \%$ from the area of the region. The wet area remains spread over the whole region, especially in the western regions, with a higher intensity than the eastern region for the years 1992, 1994, 1996 and 1998, and the SPI ranges from 0.07 to 0.52 . 
The years 2000, 2008, 2011 and 2012 have droughts spreading over the whole are, and as mentioned previously the eastern regions are drier compared to the rest of the other regions. While it spreads by $60 \%$ of the area and on all parts except the watershed center and towards the north in the year 2006 and the area covered is $10200 \mathrm{~km}^{2}$.

As for the years 2002 and 2010 the droughts are spread over the eastern part and the western part respectively by $22 \%$ and $24 \%$. While the rest of the areas are wet, with areas of $13000 \mathrm{~km}^{2}$ and $12,758 \mathrm{~km}^{2}$, respectively.

It is clear from the above that the distribution of droughts is often in the eastern regions of the watershed. While the western parts are more wet compared to those parts.

Figure 10 shows the dry areas during the period 1984-2013. As it is clear that the period of the 1980 s and 1990s, the wet areas are the dominant. While they begin to decline with the beginning of the 2000s. So, the dry areas increase in them at the expense of the wet areas.
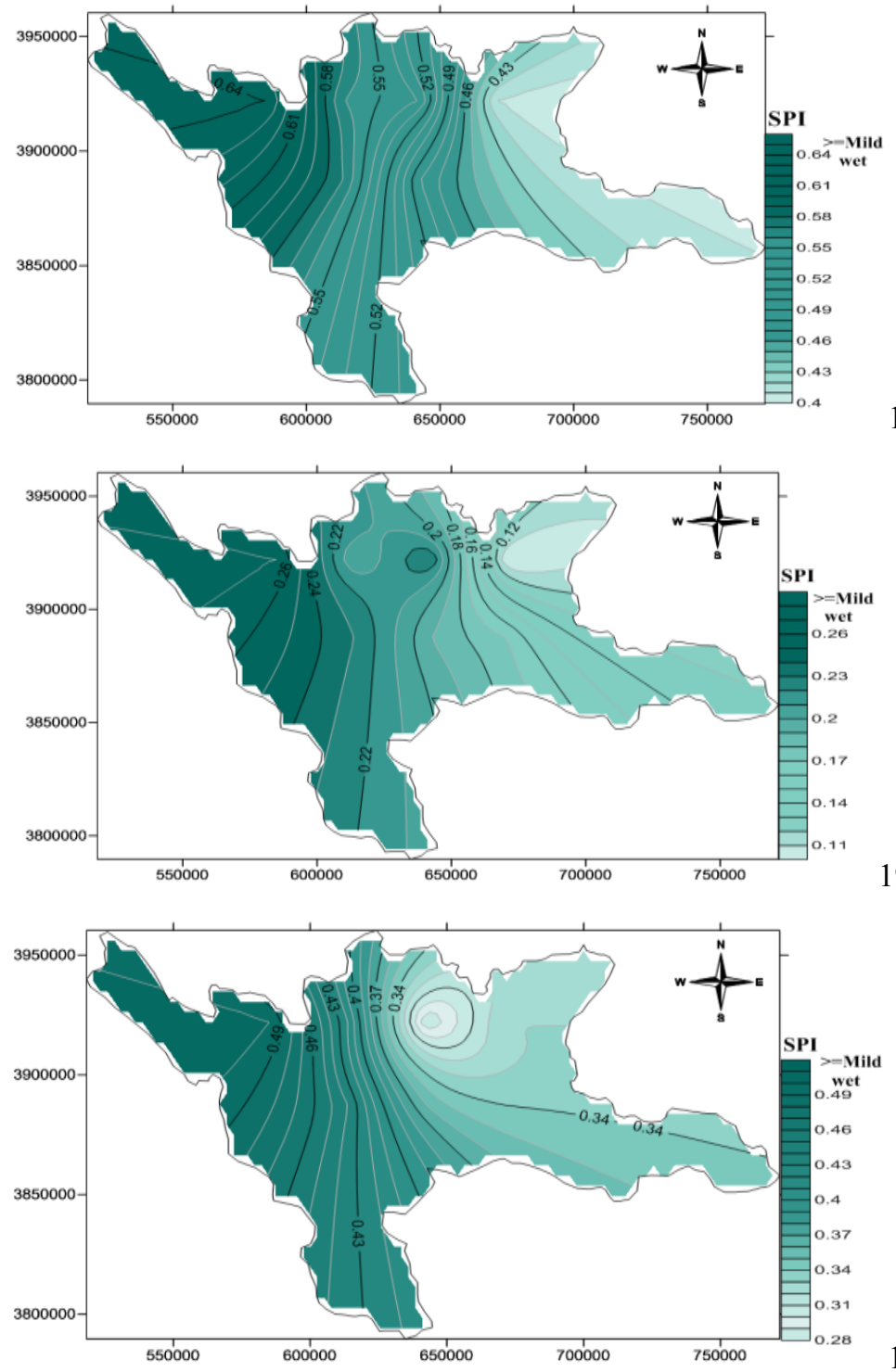

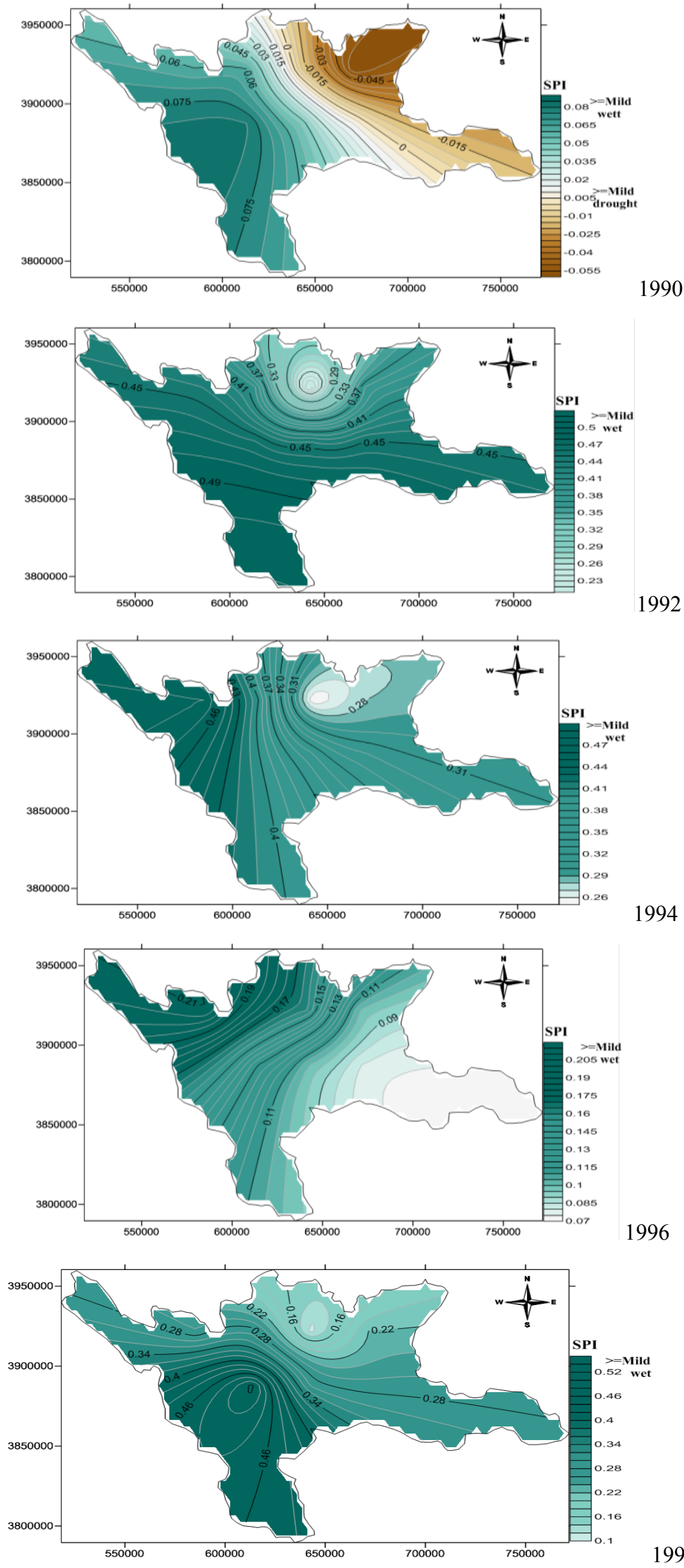

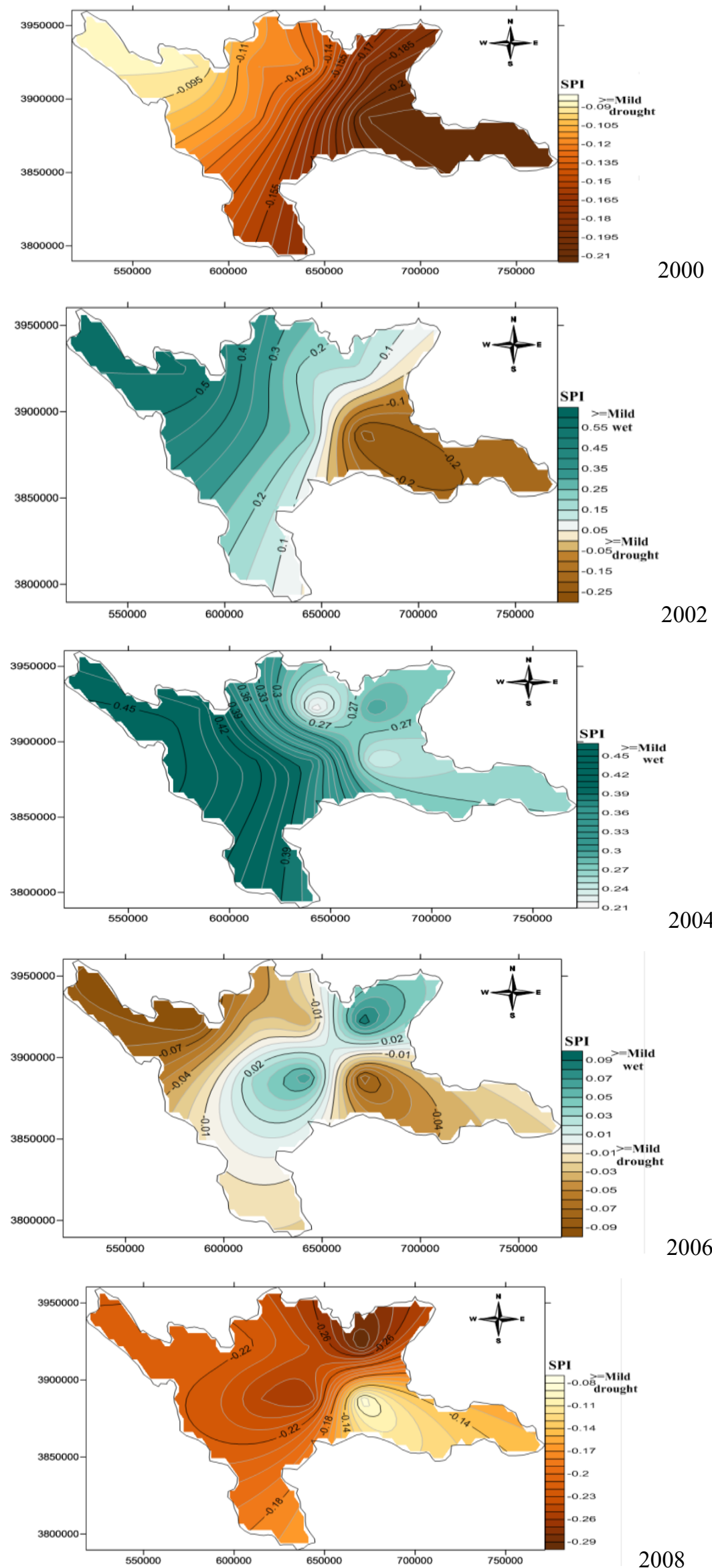

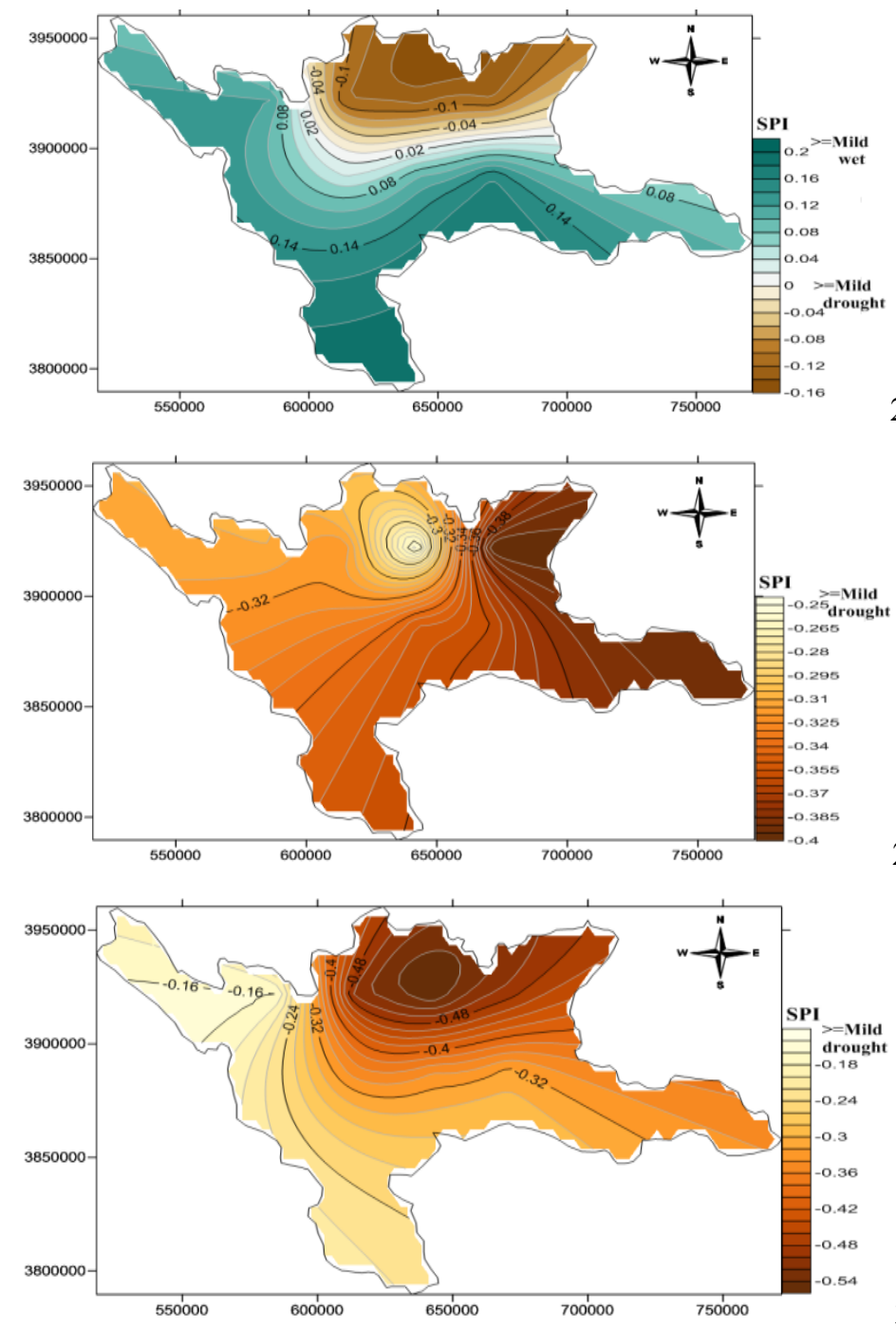

Figure 9: Spatial distribution maps of drought according to SPI for the period from 1984 to 2013.

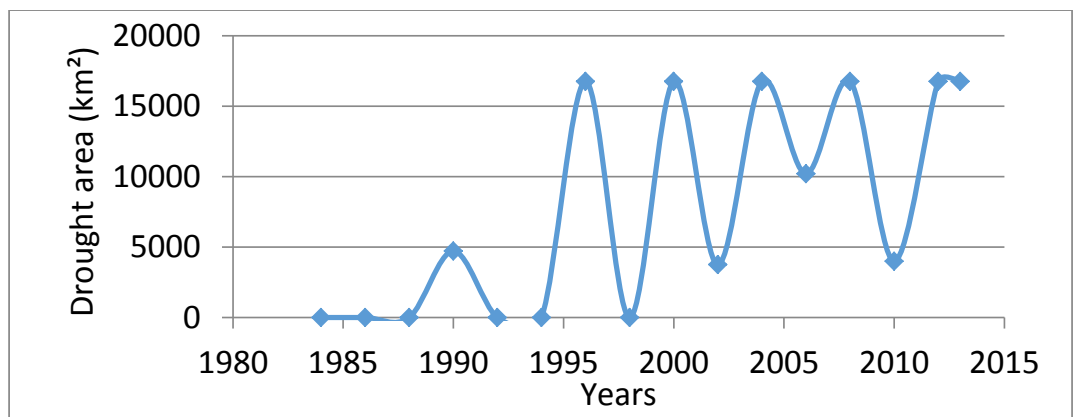

Figure 10: Drought area for the period 1984- 2013 according to results SPI.

\section{B. Spatial Distribution of RDI}

The spatial distribution of drought according to RDI had the largest share in the spreading over the watershed area in contrast to the SPI. The SPI indicated that wet areas are dominant, but these two indices agreed that the eastern part is more dry compared to the western part which is more wet. Also, the periods $2000-2010$ is the driest period compared to the eighties.

Droughts were distributed in the eastern, southern and northern parts, with $55 \%$ and 60 of the watershed area for the years 1984 and 1986. While the remaining wet area was $7570 \mathrm{~km}^{2}$ and 6780 $\mathrm{km}^{2}$ respectively. Which it is in the eastern part. While in 1988, all watershed is covered by $100 \%$ 
wet area, but it is gradually decreasing from the center to the east, and the value of the RDI ranges from 0.08 to 0.5 . For the year 1990 it is completely dry and then the years that follow it are wet, and the drought constitutes a very small percentage which is $22 \%$ and $2 \%$ for the years 1992 and 1994 , respectively. Also these areas are in the eastern watershed. The period from 1996 to 2010 is completely dry. As it spreads over the entire area by $100 \%$ and the value of the RDI ranges from 0.05 to -0.58 . It is sometimes spread in the eastern parts and sometimes in the western parts of the Watershed. Whereas the year 2013 is more than $99 \%$ wet and the index value ranges from -0.05 to 0.75. Figure 11 shows maps showing the spatial distribution of drought for the period 1984- 2013, followed by Figure 12, which shows dry areas during this period.
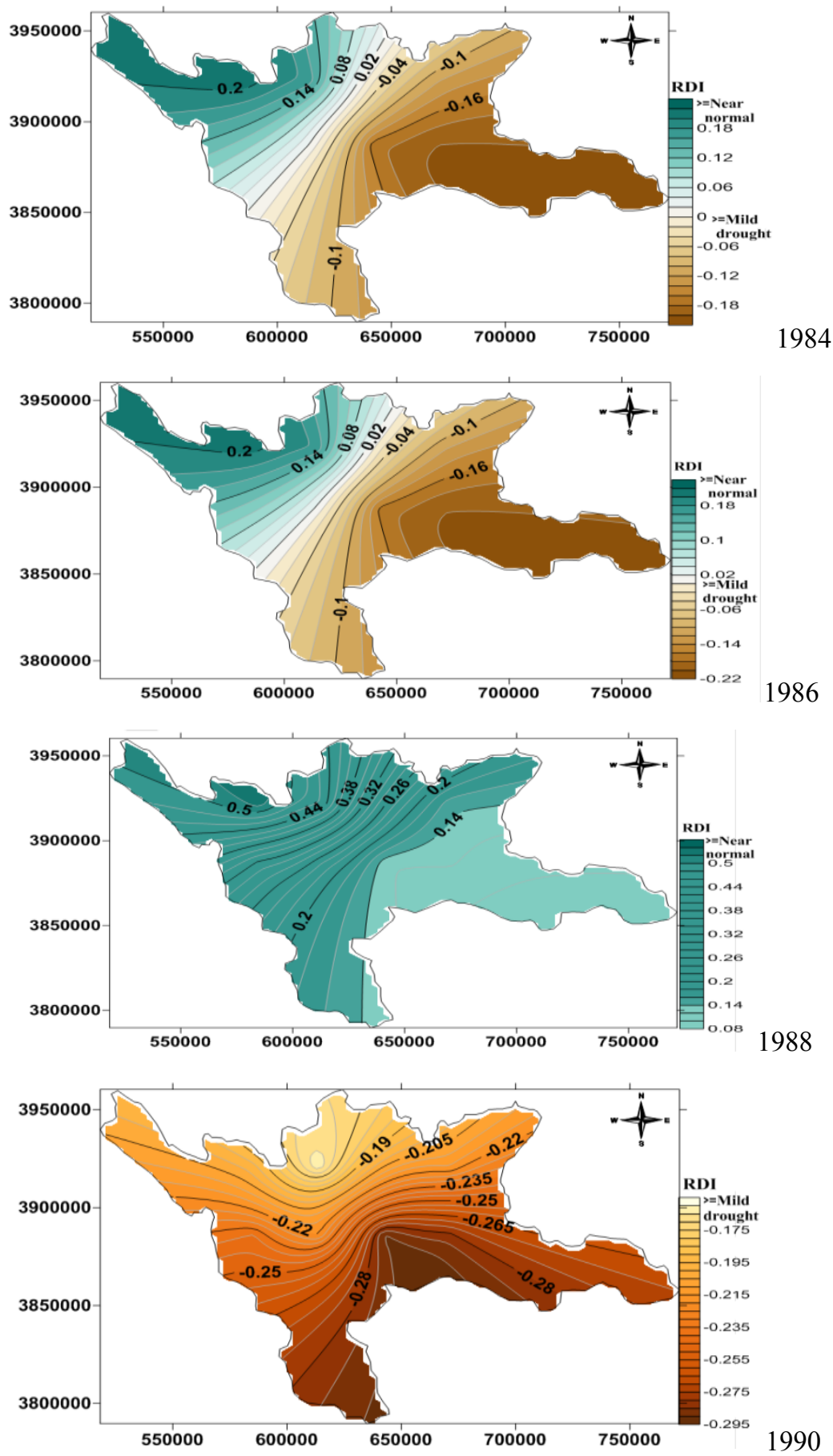

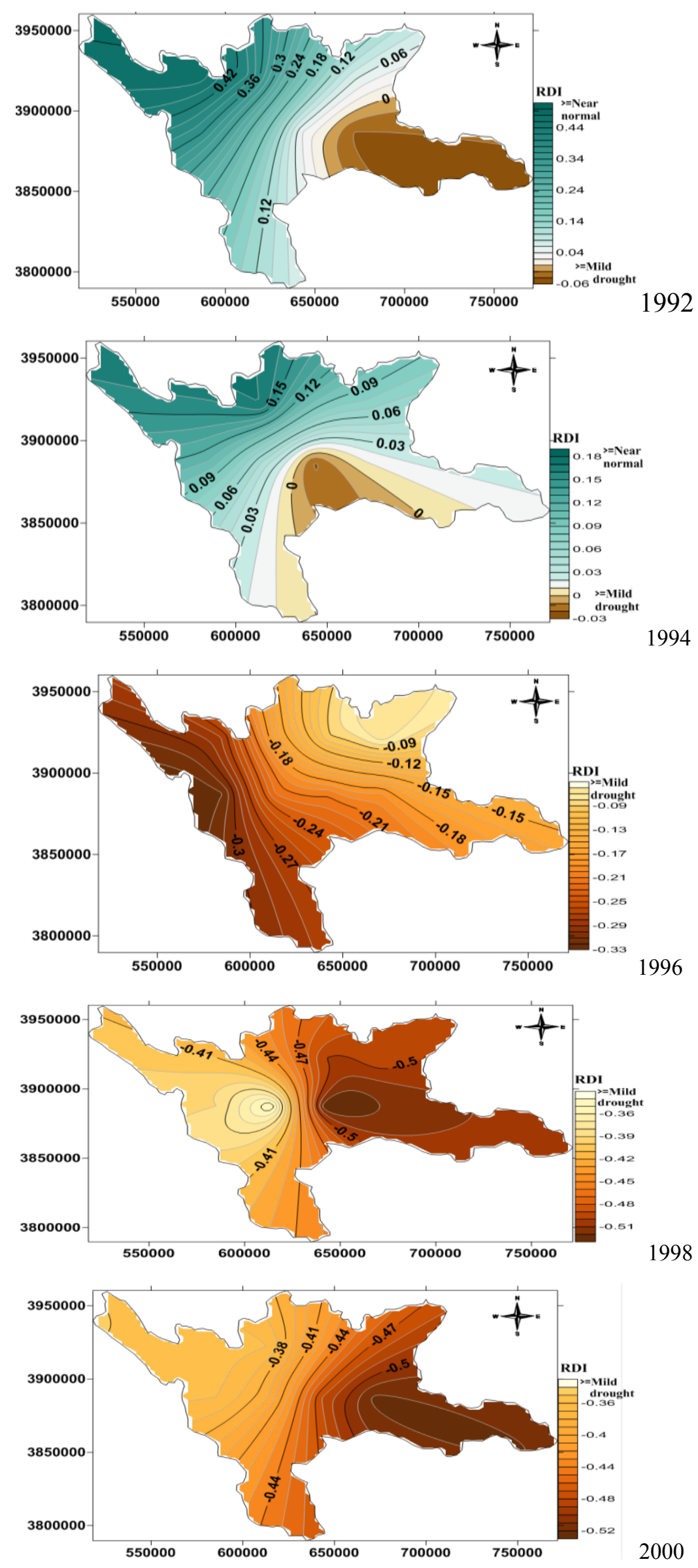

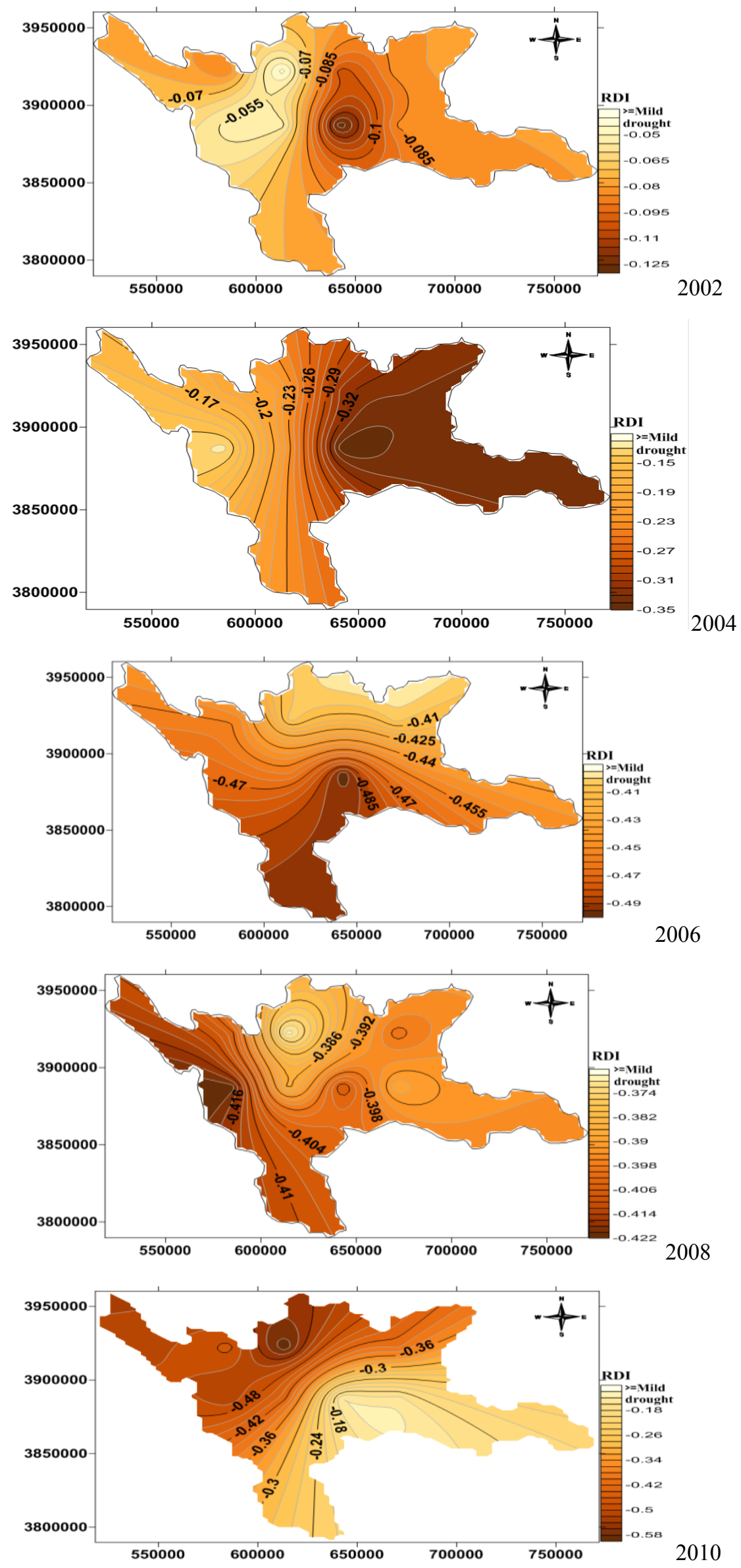

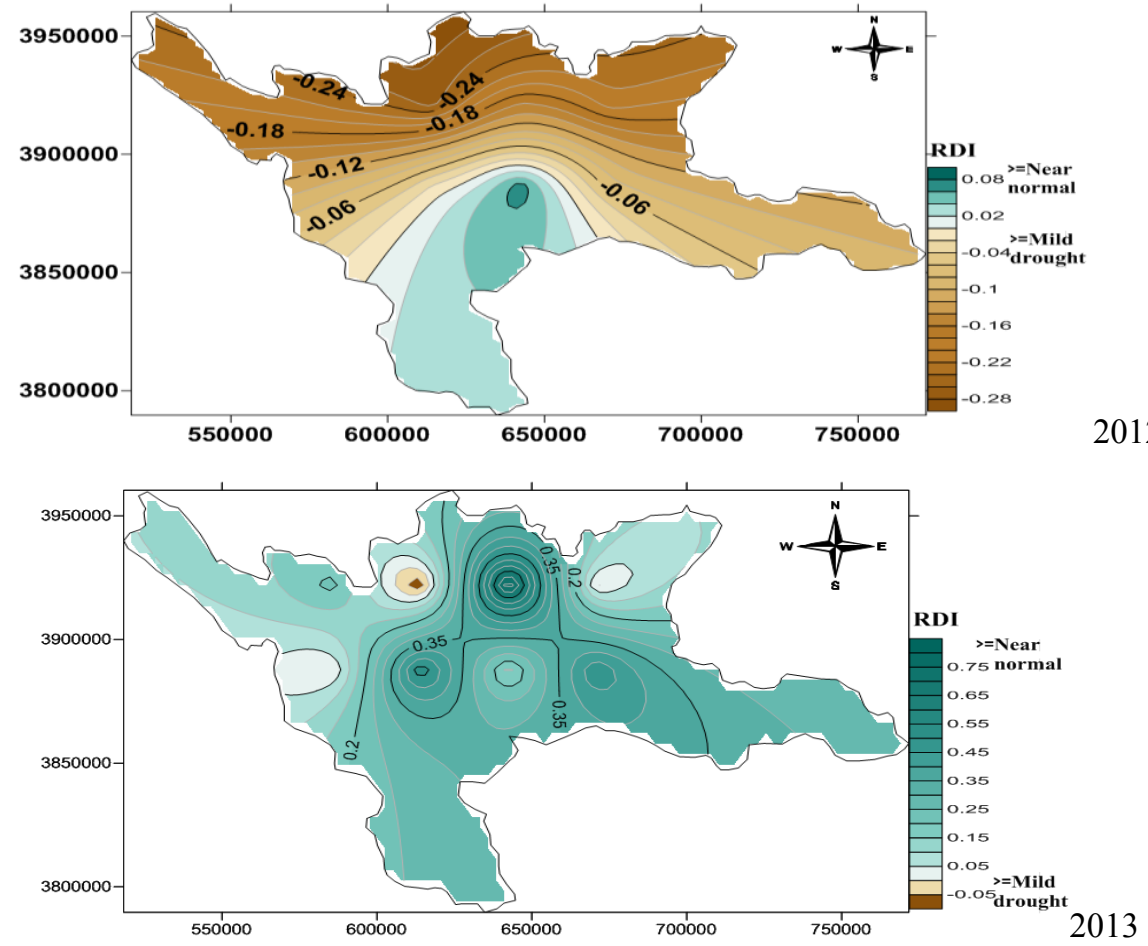

Figure 11: Spatial distribution maps of drought according to RDI for the period from 1984 to 2013.

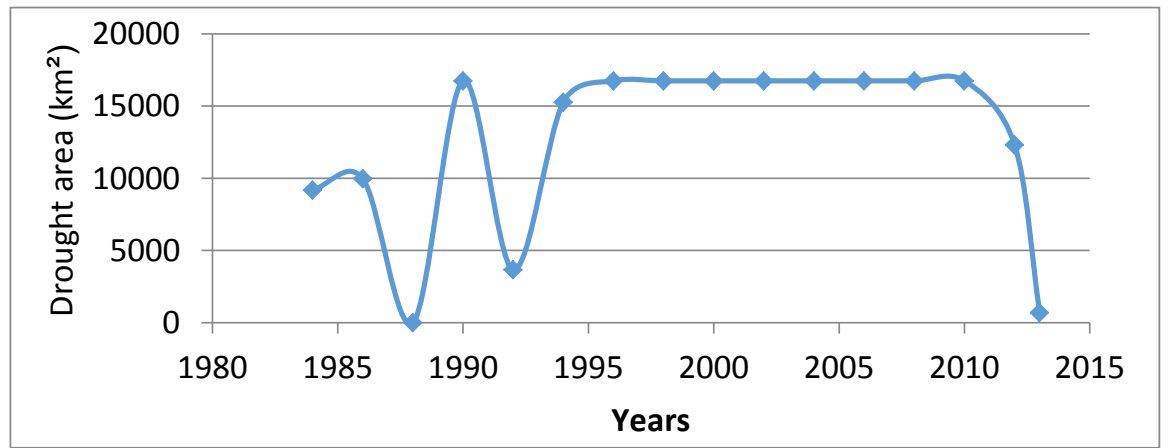

Figure 12: Drought area for the period 1984- 2013 according to results RDI.

From the analysis, the recently proposed RDI has many advantages and more reliable over the widely used indices for assessing meteorological droughts. The RDI is expected to be a more sensitive index than those related only to precipitation. This matches the researchers' studies (Tsakiris et al, 200; Alwan et al, 2018; Zarch et al, 2011).

\section{Conclusions}

This paper presents a simple and a complete picture of the occurrences and characteristics of meteorological droughts. It is based on two indices namely: SPI and RDI. Depending on monthly precipitations and air temperatures downloaded from CFSR of eight station located within the region, as well as hydrological drought index SDI with monthly streamflow data from one station. The DFPs computed for each index to determine droughts recurrence intervals and the exceedance probability. The results of these three indices are consistent in the fact that the period of the 1980s to the mid1990s is a wet period. Then the dry period begins from the mid-1990s to 2013.

RDI and SPI results for drought were not exceeding mild drought, unlike SDI which was more severe. The SDI shows many years of severe drought with moderate drought which was repeated for three consecutive years. In addition, the SPI and the SDI recorded the same percentage of dry years, which was less than the wet years. However, the RDI recorded percentage of dry years more than that of wet years. This indicates long periods of drought that are $20 \%$ higher than the other two 
indices. The spatial distribution of SPI and RDI indices shows that the western part is less dry while the eastern part is the most severe in drought. The RDI is more accurate than the other indices. It depends on two factors; namely precipitation and potential evapotranspiration. It is computed by temperatures, unlike other indices that depend on one factor.

In this paper, a frequency analysis was applied to drought durations to obtain droughts frequency. Subsequently, return periods of historical drought events shows that the region has suffered from more meteorological droughts than the hydrological drought. Nevertheless, the hydrological drought was more severe than meteorological drought. These three different drought indices provide different references for building drought early warning and mitigation systems in the basin.

\section{Acknowledgment}

The authors wish to thank the technical and faculty staff of the Department of Civil Engineering at the University of Technology-Iraq for the valuable support and scientific assistance.

\section{References}

[1] N. Zeng "Drought in the Sahel" Science, 302(5647), 999-1000, 2003.

[2] W. C. Palme "Meteorological drought, Vol. 30 "US Department of Commerce, Weather Bureau", 1965.

[3] J. V. Vogt, U. Safriel, G. Von Maltitz, Y. Sokona, R. Zougmore, G. Bastin and J. Hill "Monitoring and assessment of land degradation and desertification: towards new conceptual and integrated approaches". Land Degrad. 22(2): 150-165, $2011 \mathrm{~b}$.

[4] J. A. Dracup, K. S. Lee and E. G. Paulson "On the statistical characteristics of drought events" Water resources research, 16(2), 289-296, 1980.

[5] D. A. Wilhite and M. H. Glantz. "Understanding: the drought phenomenon: the role of definitions". Water international, 10(3), 111-120, 1985.

[6] A. K. Mishra and V. P. Singh "A review of drought concepts" Journal of hydrology, 391(1-2), 202-216, 2010.

[7] F. N. Kogan "Global drought watch from space" Bull. Am. Meteorol. Soc. 78(4): 621-636, 1997.

[8] EM-DAT. 2013, http://www.emdat.be/disaster-list

[9] A. Dai, K. E. Trenberth and T. Qian "A global dataset of Palmer Drought Severity Index for 1870-2002: Relationship with soil moisture and effects of surface warming" Journal of Hydrometeorology, 5(6), 1117-1130, 2004.

[10] I. Alwan, A. R. T. Ziboon, and A. G. Khalaf, "Comparison of Nine Meteorological Drought Indices Over Middle Euphrates Region During Period from 1988 To 2017”. International Journal of Engineering \& Technology, 7(4.20), 602-607, 2008.

[11] M. Hameed, A. Ahmadalipour and H. Moradkhani "Apprehensive drought characteristics over Iraq: results of a multidecadal spatiotemporal assessment" Geosciences, 8(2), 58, 2018.

[12] A. I., Jasim and T. A. Awchi "Rainfall Data Analysis and Study of Meteorological Draught in Iraq for the Period 1970-2010” Tikrit Journal of Engineering Sciences, 24(1), 110-121, 2017.

[13] Y. K. AL-Timimi, L. E.George and M. H. AL-Jiboori "Drought risk assessment in Iraq using remote sensing and GIS techniques" Iraqi Journal of Science, 53(5), 1078-1082, 2012.

[14] A. M. Rasheed "Analysis of rainfall drought periods in the North of Iraq using standard precipitation index (SPI) ” AL-Rafdain Engineering Journal (AREJ), 18(2), 60-72, 2010.

[15] K. A. Al-Mohseen "Frequency Analysis of Hydrologic Drought (Case Study) " AL-Rafdain Engineering Journal (AREJ), 18(6), 40-52, 2010.

[16] A. Ozkaya and Y. Zerberg "A 40-Year Analysis of the Hydrological Drought Index for the Tigris Basin, Turkey” Water, 11(4), 657, 2019.

[17] R.Soumyashri and S. P. Nagraj "Drought Analysis Based on Streamflow Drought Index (SDI) in Bhima Sub-Basin" International Journal of Advanced Engineering Research and Applications, 2(3), 154-159, 2016.

[18] I. Nalbantis "Evaluation of a hydrological drought index" European Water, 23(24), 67-77, 2008. 
[19] T. B. McKee, N. J. Doesken and J. Kleist "The relationship of drought frequency and duration to time scales" In Proceedings of the 8th Conference on Applied Climatology (Vol. 17, No. 22, pp. 179-183), 1993.

[20] M. A. Khan and A. S. Gadiwala "A Study of Drought over Sindh (Pakistan) Using Standardized Precipitation Index (SPI) 1951 to 2010”, Pakistan Journal of Meteorology, Vol. 9, Issue 18, pp.15 -22, 2013.

[21] I. Alwan, A. R. T. Ziboon, and A. G. Khalaf, "Comparison of Nine Meteorological Drought Indices Over Middle Euphrates Region During Period from 1988 To 2017" International Journal of Engineering \& Technology, 7(4.20), 602-607, 2008.

[22] A. Shahabfar and J. Eitzinger "Spatio-temporal analysis of droughts in semi-arid regions by using meteorological drought indices" Atmosphere, 4(2), 94-112, 2013.

[23] E. Yacoub and G. Tayfu "Evaluation and assessment of meteorological drought by different methods in Trarza region, Mauritania” Water Resources Management, 31(3), 825-845, 2017.

[24] R. Kumar, A. Sagar and A. S. Bist. “Assessment of Nagina Area of Distt. Bijnor U.P. on the Basis of Standard Precipitation Index (SPI) for drought Intensity" international journal of engineering sciences \& research Technology, 5(10), 18 -26, 2016.

[25] G. Tsakiris and H. Vangelis, "Towards a drought watch system based on spatial SPI" Water resources management, 18(1), 1-12, 2004.

[26] G. Tsakiris and H. J. E. W. Vangelis, "Establishing a drought index incorporating evapotranspiration" European water, 9(10), 3-11, 2005.

[27] G. Tsakiris, D. Pangalou, and Vangelis, H. "Regional drought assessment based on the Reconnaissance Drought Index (RDI) "Water resources management, 21(5), 821-833, 2007.

[28] R. Shah, V. L. Manekar, R. A. Christian and N. J. Mistry "Estimation of reconnaissance drought index (RDI) for Bhavnagar District, Gujarat, India" International Journal of Environmental, Chemical, Ecological, Geological and Geophysical Engineering, 7(7), 507-510, 2013.

[29] A. W. Al-Enezy "Relationship Between Surface and Shallow Groundwater in the Eastern Side of Shatt AlHillah, Iraq" Doctoral dissertation, M. Sc. thesis, Uni. of Baghdad, collage of science, 2012.

[30] G. Tsakiris, I. Nalbantis, D. Pangalou, D. Tigkas, and H. Vangelis, "Drought meteorological monitoring network design for the reconnaissance drought index (RDI) " In Proceedings of the 1st International Conference "Drought management: scientific and technological innovations". Zaragoza, Spain: option Méditerranéennes, series A (No. 80, p. 2008).

[31] I. Nalbantis and G. Tsakiris “Assessment of hydrological drought revisited" Water Resources Management, 23(5), 881-897, 2009.

[32] A. Ozkaya and Y. Zerberg "A 40-Year Analysis of the Hydrological Drought Index for the Tigris Basin, Turkey" Water, 11(4), 657, 2019.

[33] V. M. Yevjevich "Objective approach to definitions and investigations of continental hydrologic droughts" An. Hydrology papers (Colorado State University); no. 23, 1967.

[34] R. Downer, M. Siddiqui and V. Yevjevich "Application of runs to hydrologic droughts" Proc., Int. Hydrology Symp. Paper 63, Colorado State Univ., Fort Collins, Colo., Vol. 1, 496-505, 1967.

[35] J. Llamas and M. M. Siddiqui "Runs of precipitation series" Hydrology papers (Colorado State University); no. 33, 1969.

[36] J. A. Dracup, K. S. Lee and E. G. Paulson "On the statistical characteristics of drought events" Water resources research, 16(2), 289-296, 1980.

[37] Z. Sen "Wet and dry periods of annual flow series"Journal of the Hydraulics Division, 102(10), 1503$1514,1976$.

[38] D. M. Frick, D. Bode and J. D. Salas "Effect of drought on urban water supplies. I: Drought analysis" Journal of Hydraulic Engineering, 116(6), 733-753, 1990.

[39] B. Fernández and J. D. Salas "Return period and risk of hydrologic events. I: mathematical formulation” Journal of Hydrologic Engineering, 4(4), 297-307, 1999.

[40] H. A. Loaiciga and R. B. Leipnik, "Stochastic renewal model of low-flow streamflow sequences" Stochastic Hydrology and Hydraulics, 10(1), 65-85, 1996.

[41] E. H. Lloyd "Return period in the presence of persistence" J. Hydrol., 10(3): 202-215, 1970. 
[42] H. A. Loaiciga and M. A. Mariño "Recurrence interval of geophysical events"Journal of Water Resources Planning and Management, 117(3), 367-382, 1991.

[43] R. M. Vogel, "Reliability indices for water supply systems" Journal of Water Resources Planning and Management, 113(4), 563-579, 1987.

[44] E. M. Douglas, R. M. Vogel, and C. N. Kroll, "Impact of streamflow persistence on hydrologic design” J. Hydrologic Eng., 73, 220-227, 2002.

[45] C. H. Chung and J. D. Salas, "Drought occurrence probabilities and risks of dependent hydrologic processes" Journal of Hydrologic Engineering, 5(3), 259-268, 2000.

[46] F. A. Al-Faraj, and M. Scholz "Incorporation of the flow duration curve method within digital filtering algorithms to estimate the base flow contribution to total runoff" Water resources management, 28(15), 54775489, 2014.

[47] UN-ESCWA (United Nations Economic and Social Commission for Western Asia) and BGR (Bundesanstaltfür Geowissenschaften und Rohstoffe) "Inventory of Shared Water Resources in Western Asia. Beirut", 2013.

[48] M. S. Al-Khafaji and R. D. Al-Chalabi "Assessment and Mitigation of Streamflow and Sediment Yield under Climate Change Conditions in Diyala River Basin” Iraq. Hydrology, 6(3), 63, 2019. 